\title{
A Study of Pharmaceutical Drugs Poisoning Cases Admitted to the National Poisoning Center, Kasralainy Teaching Hospital in Cairo
}

\author{
(1) Eman Abdel Monem Abdel Rasheed ${ }^{1}$, (1) Nashwa Elmahdy¹, (1) Ezzeldin Shalaby², (1) Huda S. Karoube1, (1) Sayed M. Badawy ${ }^{1}$ \\ 1 National Center for Clinical and Environmental Toxicology, NECTR, Faculty of Medicine, Cairo University, Cairo, Egypt \\ 2 Forensic Medicine and Clinical Toxicology Department, Faculty of Medicine, Cairo University, Cairo, Egypt
}

\begin{abstract}
Aim: There is a necessity to identify the specific therapeutic drugs most frequently responsible for the acute medicinal poisoning to take up appropriate preventive efforts and management.

Materials and Methods: This study included all cases of medicinal poisoning exposures (7282 cases) presented to the emergency Department of The National Poisoning Center, Cairo University, during the period January 2016 to December 2016. The data were statistically analyzed to assess a correlation between gender, age, and most frequently seen agents.

Results: Therapeutic drugs (68\%) were the most common cause of poisoning. It was found that 53\% of medicinal poisoning patients were adults. Accidental drug agents poisoning in children younger than 4 years represented $20 \%$ of the medicinal poisoning cases. Of the patients with medicinal poisoning $74 \%$ were female and $26 \%$ were male. Detailed information on categories of drugs causing medicinal poisonings was presented. Paracetamol (9.6\%), nonsteroid anti-inflammatory drugs (9.6\%) and sedatives/hypnotics (10.7\%) were the most common drugs causing medicinal poisoning.

Conclusion: Female gender and young age are the risk factors of medicinal poisoning. The majority of poisonings is intentional poisoning in female adults. An important concern should be raised towards availability of prescription medications within the reach of children.

Keywords: Acute medicinal poisoning, epidemiology, poisoning center
\end{abstract}

\section{Introduction}

Acute poisoning following accidental and intentional ingestion of medications or drug overdoses constitutes a high degree of mortality, morbidity and health care cost worldwide (1-5). The resources of drugs poisoning vary by region and country $(6,7)$, which reflect the prescribing practice and the availability of drugs in the population (8).

Opioids and anti-depressants in the United Kingdom (UK) (9); sedatives-hypnotics and anti-psychotics in Japan (10); opioids, benzodiazepines, and anti-depressants in the United States (US) (11); anti-depressants and analgesics in Turkey (12); opioids and pesticides in Iran (6) and analgesics and non-steroidal antiinflammatory drugs (NSAIDs) followed by anti-convulsants and anti-hypertensives in Saudi Arabia (13) are the leading drugs causing to poisoning.
Drug overdoses can affect people of any age. Most of childhood poisonings are accidental, while poisoning in adolescents is mainly intentional (self-harm). Few studies have investigated the medicinal poisoning pattern in our country. There is a necessity to know the medications that contribute to poisoning cases, to take up appropriate preventive efforts and management. This study was aimed to determine the pattern of medicinal poisoning of patients who visited Kasraleiny Teaching Hospital, Cairo, for the prevention of poisoning due to pharmaceuticals.

\section{Materials and Methods}

A study was conducted in all cases of medicinal poisoning at the National Center for Clinical and Environmental Toxicology (NECTR) during the period January 2016 to December 2016. The differences between groups were investigated with statistical

Cite this article as: Rasheed EAMA, Elmahdy N, Shalaby E, Karoube HS, Badawy SM. A Study of Pharmaceutical Drugs Poisoning Cases Admitted to the National Poisoning Center, Kasralainy Teaching Hospital in Cairo. Eurasian J Emerg Med. 2020;19(1):10-5

(C) Copyright 2020 by the Emergency Medicine Physicians' Association of Turkey

Eurasian Journal of Emergency Medicine published by Galenos Publishing House. 
analysis of data taken from charts which retrospectively included age, gender and agents causing poisoning.

Patients were divided into nine major groups based on the categories of pharmaceuticals: Central nervous system agents, cardiovascular system agents, respiratory system agents, analgesics, antibiotic agents, anti-diabetics, contraceptives, gastrointestinal agents and others.

\section{Statistical Analysis}

Factors that might be associated with the poison exposure were analyzed with the Pearson $X^{2}$. Yate's correction chi-square test of Med Calc software were used for a comparison between groups. Statistical $p$ values less than 0.05 were considered significant.

The guidelines on patient consent were met. The study followed ethical principles of the Declaration of Helsinki for medical research of human subjects.

\section{Results}

The present study was conducted in 7282 patients with medicinal poisonings at the emergency department of NECTR during the period January 2016 to December 2016. Therapeutic drugs (68\%) were the most common cause of poisoning (Figure 1). Substances causing poisoning were unidentified in $4 \%$ of cases. Of the patients with medicinal poisoning $74 \%$ were female and $26 \%$ were male as shown in Table $1(p<0.0001)$. In the medicinal poisoning, adults accounted for $53 \%$ of all cases, followed by children younger than 4 years (20\%), patients with ages between $13-18$ years (19\%) and with ages between $4-12$ years (8\%).

Detailed information on pharmaceutical drug categories causing medicinal poisonings is presented (Figure 2). Therapeutic drugs were categorized into analgesics (24\%), central nervous system agents (21\%), cardiovascular system agents (7\%), respiratory system agents (6\%), antibiotics (8\%), contraceptives (8\%), antidiabetics (5\%), gastrointestinal agents (6\%) and others (15\%) $\left(X^{2}=45.630 p<0.0001\right)$.

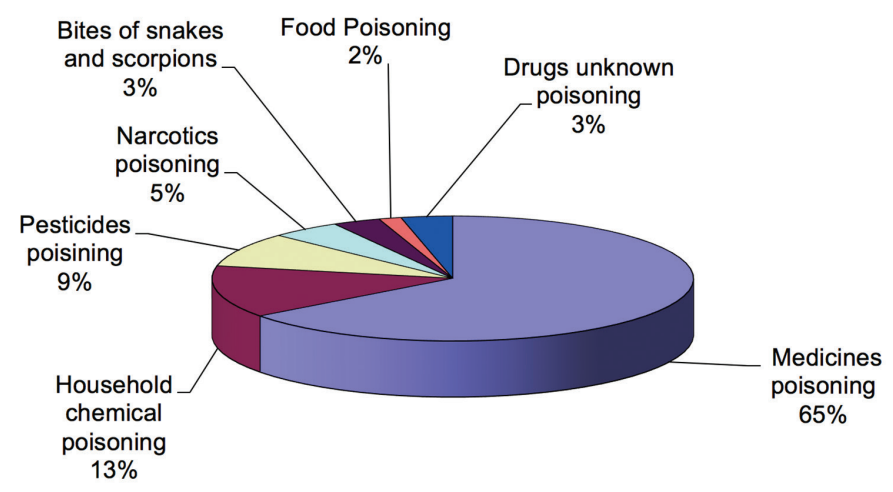

Figure 1. Distribution of poisoning types
Table 2 shows detailed information of therapeutic agents causing poisonings. Central nervous system agents were subcategorized into sedative/hypnotics (51\%), anti-psychotic (20\%), anti-epileptics (18\%) and anti-depressants (12\%) $\quad\left(X^{2}=36.386, \quad p<0.0001\right)$. Analgesics were subcategorized into Paracetamol (40\%), NSAIDs $(40 \%)$ and Acetylsalicylic acid (13\%) $\left(X^{2}=15.677, \quad p<0.0004\right)$. Cardiovascular system agents were subcategorized into antihypertension agents (49\%), anti-coagulants (16\%), $\beta$-blockers

\begin{tabular}{|c|c|c|c|}
\hline Characteristics & \multicolumn{2}{|c|}{$\begin{array}{l}\text { n, Percentage } \\
\%\end{array}$} & $\begin{array}{l}\text { Pearson } X^{2}(d f), \\
p\end{array}$ \\
\hline \multicolumn{3}{|l|}{ Gender } & \multirow{3}{*}{$\begin{array}{l}23.040(1) \\
p<0.0001\end{array}$} \\
\hline Female & 5389 & $74 \%$ & \\
\hline Male & 1893 & $26 \%$ & \\
\hline \multicolumn{3}{|l|}{ Age group } & \multirow{5}{*}{$\begin{array}{l}45.630 \\
p<0.0001\end{array}$} \\
\hline Children (<4 years) & 2693 & $20 \%$ & \\
\hline Children (4-12 years) & 914 & $8 \%$ & \\
\hline Adolescents (12-18 years) & 2039 & $19 \%$ & \\
\hline Adults (>18 years) & 5674 & $53 \%$ & \\
\hline \multicolumn{4}{|l|}{ Types of poisoning } \\
\hline Medicinal drugs & 7282 & $68 \%$ & \multirow{6}{*}{$\begin{array}{l}198.515 \\
p<0.0001\end{array}$} \\
\hline Household agents & 1487 & $13 \%$ & \\
\hline Pesticides & 993 & $9 \%$ & \\
\hline Abuse agents & 626 & $5 \%$ & \\
\hline Snakes and scorpions & 336 & $3 \%$ & \\
\hline Food poisoning & 159 & $1 \%$ & \\
\hline Reasons for poison exposure & 4374 & $39 \%$ & \multirow{3}{*}{$\begin{array}{l}4.840(1) \\
p=0.0278\end{array}$} \\
\hline Accidental & 6946 & $61 \%$ & \\
\hline Intentional & - & - & \\
\hline
\end{tabular}

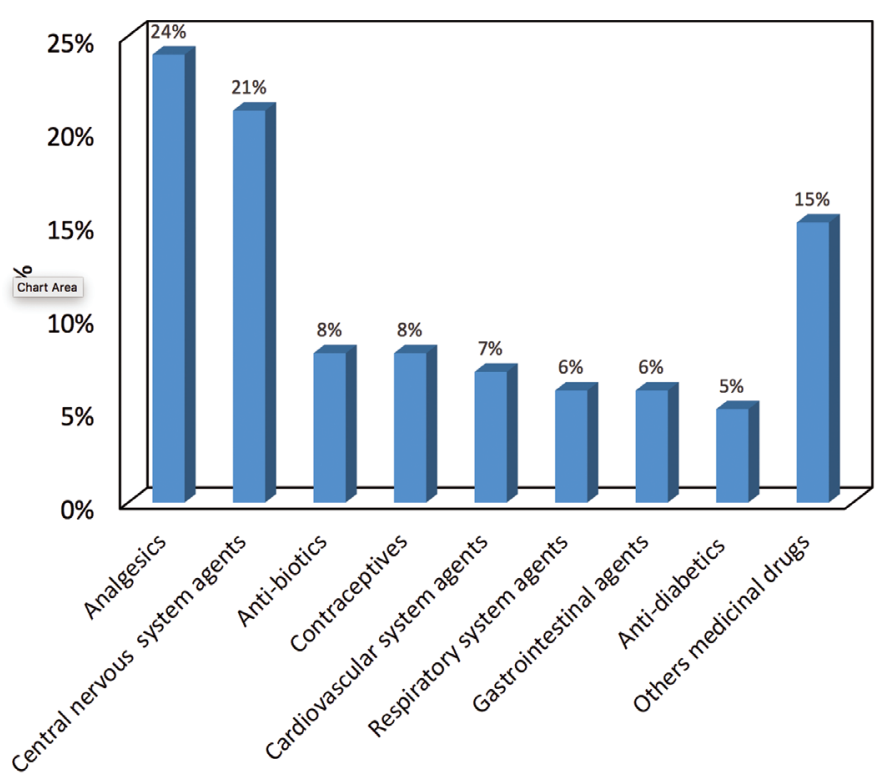

Figure 2. Distribution of medicinal poisoning 
(13\%), cardiotonic agent (11\%), medications for hypotension (9\%), and anti-hypertensive agents $(49 \%)\left(X^{2}=56.305, p<0.0001\right)$. Respiratory system agents were subcategorized into theophylline (71\%) and asthma agents (19\%) $\quad\left(X^{2}=30.044, \quad p<0.0001\right)$. Gastrointestinal agents were subcategorized into anti-parasitics (42\%), anti-emetics (18\%), anti-cholinergics (13\%) and anti-acids (13\%) $\left(X^{2}=26.837, p<0.0001\right)$.

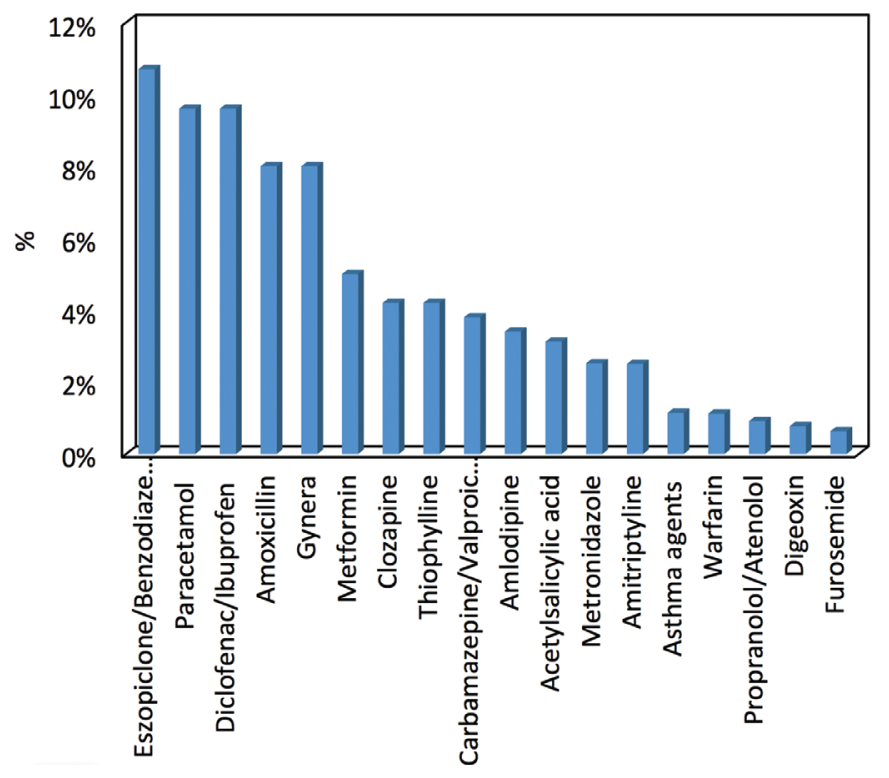

Figure 3. Most frequent agents causing poisonings

\section{Discussion}

The most common poisoning type was medicinal poisoning (68\%) in our study. In agreement with other studies, medicinal drugs were the main toxic agents (14-17). Overdoses of drugs can be either accidental or intentional. Drug overdoses affect people of any age. Intentional drug overdoses are most common in female adults, whereas accidental drug overdoses are most common in very young children. Accidental drug agents poisoning in children younger than 4 years represents $20 \%$ of the medicinal poisoning cases. Drug overdoses in children are generally caused when medication is accidentally left within the child's reach. Children younger than 4 years tend to place everything they find into their mouths.

Drug overdose due to suicide attempt is more common in adolescents and adults. Patients with drug overdose suffer from mental health conditions. Many intentional poisoning patients are unwilling to give reliable history.

Of the patients with medicinal poisoning $74 \%$ were female and $26 \%$ were male $(p<0.0001)$ which was similar to results found in other countries (14). Females are more likely to expose to emotional symptoms of stress or strain than males.

Paracetamol and NSAIDs (19.2\%) were the most common pharmaceutical poisons (Figure 3). As similar, the American

\begin{tabular}{|c|c|c|c|}
\hline Most frequent agents ${ }^{*}$ & $\%$ & Sub Cataegories & Cataegories \\
\hline Benzodiazepine, eszopiclone & 10.7 & Sedatives/hypnotics & Central nervous system agents \\
\hline Diclofenac, ibuprofen & 9.6 & NSAIDS & Analgesics \\
\hline Amoxicillin & 8 & Semisynthetic penicillins & Anti-biotics \\
\hline Metformin & 5 & Anti-type 2 diabetes & Anti-diabetics \\
\hline Clozapine & 4.2 & Anti-psychotic & Central nervous system agents \\
\hline Theophylline & 4.2 & Bronchodilator & Respiratory system agents \\
\hline Carbamazepine, valproic acid & 3.8 & Anti-epileptic & Central nervous system agents \\
\hline Amitriptyline & 2.5 & Anti-depressant & Cardiovascular system agents \\
\hline Asthma agents & 1.14 & Asthma agents & Cardiovascular system agents \\
\hline Warfarin & 1.12 & Anti-coagulant & Cardiovascular system agents \\
\hline Propranolol/Atenolol & 0.91 & B-blockers & Cardiovascular system agents \\
\hline Digoxin & 0.77 & Cardiotonic agent & Cardiovascular system agents \\
\hline Furosemide & 0.63 & Anti-hypotension & Cardiovascular system agents \\
\hline
\end{tabular}


Association of Poison Control Centers (AAPCC) (18) and a review of a toxicology cases (19) reported that the most common drugs causing to poisoning were analgesics, sedatives, antipsychotics and anti-depressants. Analgesics and anti-depressants are the most common among single agent ingestions causing acute poisoning in Turkey (12). A previous study reported that paracetamol, NSAIDs and psychoactive drugs were the most common drug poisoning in the UK (20). Acetaminophen poisoning may occur either as a result of acute ingestion or following cumulative effects (21). Acetaminophen poisoning is the most common cause of drug-associated hepatitis worldwide (21) and acute liver failure requiring transplantation of liver in the UK and the US (22-24). A decrease in analgesic overdose deaths and liver transplantation cases (20) were reported in UK after legislation of analgesics pack sizes which limited the number of paracetamol tablets in packs, was promulgated.

The most common cardiovascular system drugs causing poisoning were anti-hypertensive agents (Amlodipine) (49\%), anti-coagulants (Warfarin) (16\%) and $\beta$-blockers (Propranolol/ Atenolol) $(13 \%)(p<0.0001)$. The most popular anti-hypertensive medication used to treat high blood pressure and Coronary Artery disease is Amlodipine. Amlodipine, sold under the brand name of "Norvasc", is a commonly prescribed long-acting calcium channel blocker. Its toxicity is the leading cause of mortality resulting from drug overdose seen in the cardiovascular medicine $(25,26)$. Warfarin is a vitamin $\mathrm{K}$ antagonist which is used as an anti-coagulant for treatment of coagulopathic and thromboembolic disorders. Warfarin toxicity can be seen due to intentional adult overdose, unintentional overdose/toxicity, and pediatric ingestion by accident (27). In 2014, the AAPCC reported 1,766 single exposures to warfarin and 181 exposures to superwarfarin rodenticides. Beta-blocker drugs are a common cause of poisoning. Propranolol and Atenolol possess betaadrenergic antagonistic properties that increase their potential toxicity with significant morbidity and mortality. Overdose of agents with membrane stabilizing activity (eg, Propranolol/ Atenolol) can cause significant cardiovascular morbidity. In 2015, According to AAPCC database, 10,577 single- exposures to betablockers were reported. Of all the beta-blockers, propranolol accounts for the majority of cases with beta-blocker toxicity (28).

Theophylline (71\%) was found to be the most common respiratory system agent causing poisoning which was followed by asthma agents $(19 \%)(p<0.0001)$. Theophylline is primarily used as a bronchodilator for patients with asthma and Chronic Obstructive Pulmonary disease (COPD). Theophylline has a narrow therapeutic window, and even levels slightly above this therapeutic window can cause many adverse effects in the setting of acute and chronic toxicity (29). In the US, toxic exposures to theophylline have decreased significantly since its management for asthma and COPD has declined (29).

Metformin (anti-hyperglycaemic agent), is the most frequent anti-diabetic causing poisoning which accounts for $5 \%$ of the medicinal poisonings. The high rate of severe lactic acidosis caused by Metformin poisoning led to the withdrawal of it from the US (30).

Metronidazole (42\%) is the most frequent gastrointestinal poisoning agent and have been reported in suicide attempts and accidental overdoses. Metronidazole is a very common worldwide anti-bacterial and anti-protozoal which is used more than 50 years (31). The mechanism of toxicity is uncertain. Metronidazole may bind to benzodiazepine receptor sites on gamma-aminobutyric acid channels of central vestibular inhibitory and cerebellar interneurons. It was found that the administration of a benzodiazepine shortened the duration of clinical signs related to metronidazole toxicity (32).

Benzodiazepines and Eszopiclone (non-benzodiazepine) sedatives/hypnotics (51\%) were the most common among central nervous system agents causing poisoning, followed by antipsychotics (20\%), anti-epileptics (18\%) and anti-depressants (12\%) $(p<0.0001)$. Sedative-hypnotic drugs become the preferred drugs for intentional overdose due to their availability and widespread use (33). The frequent prescription of psychiatric illnesses drugs has increased the incidence and the risk of accidental overdose (33). Patients suffering from epilepsy and some mental disorders, who use anti-epileptic drugs, are at increased risk of suicidal attempts. Anti-epileptic drugs (Carbamazepine/Valproic acid) constitute $3.8 \%$ of all causes with poisoning, which is similar in other countries. Annual report of the AAPCC states that antiepileptic drugs comprise $3.2 \%$ of all causes of poisoning in adults (34). In Iran, anti-epileptic drugs poisoning accounted for $4.8 \%$ of all the pharmaceutical intoxications (35). In Turkey, $6.7 \%$ of medicinal intoxications was due to anti-epileptic drugs (36).

The incidence of cases with contraceptive overdose represented $8 \%$ of all poisoning cases. Gynera is the most common progestin which is widely used; however, significant acute toxicity has not been reported after overdose.

The incidence of cases with antibiotic overdose represented 8\% of all poisoning cases. Amoxicillin is the most common antibiotic used in primary care. The amoxicillin overdoses have the potential to produce moderate and severe toxicity (37).

There are several causes of medicinal poisoning including using of wrong medicines, their easy availability at homes and suicide attempts in adults. The prevention of medicinal poisoning should merit high priority in the preventive efforts 
and educational interventions to reduce the medicinal poisoning includes a change in dose of tablet, giving education, a change in the maximum daily dose, enhanced labeling and storing the drugs at homes far from the reach of children.

\section{Study Limitations}

Data taken from the charts retrospectively, were limited to therapeutic drug poisoning cases. Poisoning cases by drugs of abuse were not included in the study. The study excluded recorded calls of poisoned patients out-of-hospital who sought the advice from Emergency Medical Information Center. The percentage of intentional medicinal poisoning may not include all suicidal patients. Most self-poisoning patients were uncooperative to give reliable history.

\section{Conclusion}

The risk factors of poisoning are female gender and young age. An important concern towards drugs and abuse agents, which were available at homes within the reach of children, should be raised. The following conclusions were reached: (1) The most common type of poisoning was medicinal poisoning, (2) there was higher incidence of medicinal poisoning in females than in males, (3) the majority of poisonings was intentional poisoning in female adults, followed by accidental poisoning in children younger than 4 years (4) analgesics and central nervous system agents were the most common medicinal poisons and (5) Paracetamol, NSAID and sedatives/hypnotics were the most frequent poisoning therapeutics agents.

\section{Ethics}

Ethics Committee Approval: Retrospective study.

Informed Consent: The guidelines on patient consent were met.

Peer-review: Externally peer-reviewed.

\section{Authorship Contributions}

Concept: E.A.M.A.R., Design: E.A.M.A.R., S.M.B., Data Collection or Processing: E.A.M.A.R., S.M.B., Analysis or Interpretation: N.E., A.S.G., S.M.B., Literature Search: S.M.B., Writing: N.E., A.S.G., S.M.B., E.S., H.S.K.

Conflict of Interest: No conflict of interest was declared by the authors.

Financial Disclosure: The authors declared that this study received no financial support.

\section{References}

1. McCaig LF, Burt CW. Poisoning-related visits to emergency departments in the United States, 1993-1996. J Toxicol Clin Toxicol. 1999;37:817-26.

2. Mowry JB, Spyker DA, Brooks DE, McMillan N, Schauben JL. Annual Report of the American Association of Poison Control Centers' National Poison Data
System (NPDS): 32nd Annual Report. Clinical Toxicology (Phila). 2015;53:9621147.

3. Sinyor M, Howlett A, Cheung AH, Schaffer A. Substances used in completed suicide by overdose in Toronto: an observational study of coroner's data. Canadian Journal of Psychiatry. 2012;57:184-91.

4. Susnjara IM, Smoljanović A, Gojanović MD. Drug related deaths in the SplitDalmatia County 1997-2007. Collegium Antropologicum. 2011;35:823-8.

5. Warner M, Chen LH, Makuc DM, Anderson RN, Miniño AM. Drug poisoning deaths in the United States, 1980-2008. NCHS Data Brief. 2011;1-8.

6. Mehrpour O, Akbari A, Jahani F, Amirabadizadeh A, Allahyari E, Mansouri $\mathrm{B}$, et al. Epidemiological and clinical profiles of acute poisoning in patients admitted to the intensive care unit in eastern Iran (2010 to 2017). BMC Emergency Medicine. 2018;19:30.

7. Eddleston M. Patterns and problems of deliberate self-poisoning in the developing world. Qjm. 2000;93:715-31.

8. Okumura Y, Sakata N, Takahashi K, Nishi D, Tachimori H. Epidemiology of overdose episodes from the period prior to hospitalization for drug poisoning until discharge in Japan: An exploratory descriptive study using a nationwide claims database. Journal of Epidemiology. 2017;27:373-80.

9. Corkery J, Claridge H, Loi B, Goodair C, Schifano F. Drug-Related Deaths in the UK. London: International Centre for Drug Policy. ISSN 978-189-77789-2. January-December 2012:2014.

10. Hikiji W, Okumura Y, Matsumoto T, Tanifuji T, Suzuki H, Takeshima T, et al. Identification of psychotropic drugs attributed to fatal overdose: a case-control study by data from the Tokyo Medical Examiner's Office and prescriptions. Psychiatria Neurologia Jpn. 2016;118:3-13.

11. Jones CM, Mack KA, Paulozzi LJ. Pharmaceutical overdose deaths, United States, 2010. JAMA. 2013;309:657-9.

12. Yaylaci S, Genc AB, Demir MV, Cinemre H, Tamer A. Retrospective evaluation of patients at follow-up with acute poisoning in Intensive Care Unit. Niger J Clin Pract. 2016;19:223-6.

13. Bakhaidar M, Jan S, Farahat F, Attar A, Alsaywid B, Abuznadah W. Pattern of Drug Overdose and Chemical Poisoning Among Patients Attending an Emergency Department, Western Saudi Arabia. J Community Health. 2015;40:57-61.

14. Tüfekçi IB, Curgunlu A, Sirin F. Characteristics of acute adult poisoning cases admitted to a university hospital in Istanbul. Human Experimental Toxicology. 2004;23:347-51.

15. Viertel A, Weidmann E, Brodt HR. [Cases of acute poisoning admitted to a medical intensive care unit]. Deutsche Medizinische Wochenschrift. 2001;126:1159-63.

16. Hanssens Y, Deleu D, Taqi A. Etiologic and demographic characteristics of poisoning: a prospective hospital-based study in Oman. Clinical Toxicology. 2001;39:371-80.

17. Islambulchilar M, Islambulchilar Z, Kargar-Maher MH. Acute adult poisoning cases admitted to a university hospital in Tabriz, Iran. Human Experimental Toxicology. 2009;28:185-90.

18. Gummin DD, Mowry JB, Spyker DA, Brooks DE, Fraser MO, Banner W. 2016 Annual Report of the American Association of Poison Control Centers National Poison Data System (NPDS): 34th Annual Report. Clin Toxicol (Phila). 2017; 55:1072-252.

19. Farrugia LA, Rhyee SH, Calello DP, Campleman SL, Riederer AM, Malashock HR, et al. The Toxicology Investigators Consortium Case Registry-the 2016 Experience. J Med Toxicol. 2017;13:203-26

20. Hawton K, Bergen H, Simkin S, Dodd S, Pocock P, Bernal W, et al. Long term effect of reduced pack sizes of paracetamol on poisoning deaths and liver transplant activity in England and Wales: interrupted time series analyses. BMJ. 2013;7:346:f403

21. Kumar R, Premnath U. Novel Regimens in the Treatment of Paracetamol (Acetaminophen) Poisoning. Journal of The Association of Physicians of India. 2017;65:71-8. 
22. Bower WA, Johns M, Margolis HS, Williams IT, Bell BP. Population-based surveillance for acute liver failure. Am J Gastroenterol. 2007;102:2459-63.

23. Saoraya J, Inboriboon PC. Acute Poisoning Surveillance in Thailand: The Current State of Affairs and a Vision for the Future. ISRN Emergency Medicine 2013;2013:9.

24. Larson AM, Polson J, Fontana RJ, Davern TJ, Lalani E, Hynan LS, et al. Acetaminophen-induced acute liver failure: results of a United States multicenter, prospective study. Hepatology. 2005;42:1364-72.

25. Upreti V, Ratheesh V, Dhulland P, Handa A. Shock due to amlodipine overdose. Indian J Crit Care Med. 2013;17:375-7.

26. DeWitt CR, Walksman JC. Pharmacology, pathophysiology and management of calcium channel blocker and $\beta$-blocker toxicity. Toxicol Rev. 2004;23:22338.

27. Deaton JG, Nappe TM. Warfarin Toxicity. StatPearls [Internet], Jun 7 20202019.

28. Menke NB, Walsh SJ, King AM. Cardiotoxicodynamics: Toxicity of Cardiovascular Xenobiotics. Emerg Med Clin North Am. 2015;33:563-95.

29. Jonathan D. Journey; Thomas P. Bentley. Theophylline Toxicity. StatPearls [Internet], November 25, 2019.

30. Shun C. Kwong, Jeffrey Brubacher Phenformin and lactic acidosis: A case report and review. Journal of Emergency Medicine. 1998;16:881-6.
31. Agarwal A, Kanekar S, Sabat S, Thamburaj K. Metronidazole-Induced Cerebellar Toxicity. Neurol Int. 2016;8:6365.

32. Evans J, Levesque D, Knowles K, Longshore R, Plummer S. Diazepam as a Treatment for Metronidazole Toxicosis in Dogs: A Retrospective Study of 21 Cases. J Vet Intern Med. 2003;17:304-10

33. Sharma S, Kukreti P, Kataria D. Sedative hypnotics overdose: Epidemiology, diagnosis and management. Indian Journal of Medical Specialities. 2018;9:134-9.

34. Watson WA, Litovitz TL, Klein-Schwartz W, Rodgers GC Jr, Youniss J, Reid N, et al. 2003 Annual Report of the American Association of Poison Control Centers Toxic Exposure Surveillance System. Am J Emerg Med. 2004;22:335-404.

35. Hassanian-Moghaddam H, Zarei MR, Kargar M, Sarjami S, Rasouli MR. Factors associated with non benzodiazepine antiepileptic drug intoxication: Analysis of 9,809 registered cases of drug poisoning. Epilepsia. 2010;51:979-83.

36. Hassanian-Moghaddam H, Zarei MR, Kargar M, Sarjami S, Rasouli MR. Factors associated with nonbenzodiazepine antiepileptic drug intoxication: Analysis of 9,809 registered cases of drug poisoning. Epilepsia. 2010;51:979-83.

37. Gillies M, Ranakusuma A, Hoffmann T, Thorning S, McGuire T, Glasziou P, et al. Common harms from amoxicillin: a systematic review and metaanalysis of randomized placebo-controlled trials for any indication CMAJ. 2015;187:E21-31. 